\title{
Editorial
}

\author{
Benedikt J. Braun
}

\section{Young surgery and the bottleneck of finding new blood}

https://doi.org/10.1515/iss-2018-0025

Recruiting young surgeons remains one of the major challenges of surgery in Germany today. Professional institutions predict up to $23 \%$ missing board certified surgeons until 2030 in Germany [1]. Already today, depending on the geographic location and regional circumstances established surgical training positions remain vacant due to a lack of suitable applicants [2]. While there is a slight increase $(+2.3 \%)$ in the overall number of surgeons according to the official statistics of the German Chamber of Physicians, these numbers do not take into account working hours, or actual employment, and a substantial portion of this slight increase is met through the recruitment of foreign surgeons [3]. In part, this creates additional language and system-related challenges, but also raises ethical concerns, as these surgeons come from medical systems that face their own recruitment challenges. Furthermore, employment numbers do not take into account the level of motivation and qualification of the applicant that has been reported as decreasing in a recent survey of leading hospital surgeons [4]. In Germany on the other hand, the initial motivation of young medical students towards a career in surgery is high, but steadily decreases, especially when they are introduced to the surgical daily routine during their final year, a time when the majority of students make their final decision concerning their prospective medical subspecialty training [5].

A potential cause for the problem could be the relative discontent of current residents with their training situation [6], but especially with their surrounding working conditions, that is then noticed by the medical students during their final year. Furthermore, the surrounding conditions might significantly affect their perceived satisfaction with a surgical career, but also the often-cited work-life balance in general [7]. This is of great importance to the potential next generation of surgeons as large student surveys show, that work-life balance, as well as related issues, such as structured overtime and family friendliness, are the main drivers when it comes to choosing a future medical subspecialty [8]. On top of that, studies have shown that many residents fear that the economic situation of their hospital directly influences their surgical education [9], yet simple measures such as daycare centers could improve both the hospitals economic situation, as well as employee satisfaction, as over $60 \%$ of surgical residents become parents during their residency training [10].

If there is discontent and solutions can be found, the key question remains; why is there not more change and more general political, but also professional societal participation, especially of young surgeons to actively change their working conditions? A question that was actively discussed during the last German Surgical Society Meeting [11]. Many of the surgical societies have wonderful opportunities to actively change working conditions, improve surgical training and tackle the looming gap of young surgical residents. The aim of this Special Issue is thus to raise awareness for this important topic, introduce readers to the personal and general benefits of participating in societal work and introduce current methods to improve surgical training related to both surgical skills, as well as surrounding conditions, in Germany and also in other countries.

It is the hope of the authors, that it will not only reflect the challenges facing surgery in general and young surgeons in particular, but provide an insight into different aspects of surgical training and its surrounding conditions, to look towards training methods in different countries near and far and to ultimately invite more young surgeons to actively participate in political work and inspire us all to create a better work and life environment for the next generation of young surgeons.

Acknowledgments: All the contributors of this Special Issue express their thanks to the German Surgical Society, the special Surgical Societies and the Berufsverband for the organization and realization of professional workshops, congresses and surveys, as well as the continued support towards the Young Surgeon Organizations. Special thanks also to Prof. Jähne and the entire Innovative Surgical 
Sciences (ISS) team for providing us with the opportunity to arrange our very own young surgeon special issue.

\section{Author Statement}

Research funding: Author states no funding involved. Conflict of interest: The author is a surgical resident in training himself, also he is a Speaker of the Young Surgeon Representatives German Surgical Society, and Berufsverband German Surgery.

\section{Publication Funding}

The German Society of Surgery funded the article processing charges of this article.

\section{References}

[1] Wirtschaftsforschung WIFOR. Price Waterhouse Coopers [cited 2018 July 28]. Available from: https://www.pwc.de/de/gesundheitswesen-und-pharma/assets/fachkraeftemangel.pdf.

[2] Brauer RB, Harnoss JC, Lang J, Harnoß J, Raschke R, Flemming $S$, et al. Quality and quality assurance of teaching in surgery recommendations from a workshop of the surgical cooperative for quality assurance. Zentralbl Chir 2010;135:18-24.

[3] Bundesärztekammer. Ärztestatistik zum 31. Dezember 2017 [cited 2018 July 28]. Available from: https://www.bundesaerztekammer.de/fileadmin/user_upload/downloads/pdf-Ordner/ Statistik2017/Stat17AbbTab.pdf.
[4] Vallböhmer D, Fuchs H, Krones CJ, Dittmar R. „Nehmen wir jetzt jeden?" - Eine Umfrage in deutschen chirurgischen Kliniken. Passion Chirurgie 2018;8:Artikel 04_02.

[5] Gartmeier M, Epstein N, Berberat P, Fischer MR. Medizinstudium: Fakten statt Mythen. Dtsch Arztebl 2017;114:A-1799/ B-1532/C-1501.

[6] Roeth AA, Mille M. What do young surgeons want? Modern requirements for senior surgeons. Zentralbl Chir 2018; 143:50-4.

[7] Braun BJ, Fritz T, Lutz B, Röth A, Anetsberger S, Kokemohr P, et al. Work life balance. thoughts of the young surgeon representatives of the german surgical society. Chirurg 2018;89:1009-12.

[8] Kasch R, Engelhardt M, Förch M, Merk H, Walcher F, Fröhlich S. Physician shortage: how to prevent generation y from staying away - results of a nationwide survey. Zentralbl Chir 2016;141:190-6.

[9] Krüger M. Chirurgie 4.0 - Herausforderungen an die Nachwuchsarbeit. Passion Chirurgie 2017;7:Artikel 04_04.

[10] Depeweg D, Achatz G, Liebig K, Lorenz O. The young resident between work and family. Unfallchirurg 2013;116:15.

[11] Faber SO, Braun BJ. Nachwuchssitzungen auf dem 135. Kongress der Deutschen Gesellschaft für Chirurgie. Passion Chirurgie 2018;8:28-30.

Corresponding author: Benedikt J. Braun, Department of Trauma, Hand and Reconstructive Surgery, Saarland University Hospital, Building 57, Kirrbergerstr. 1, 66421 Homburg, Germany, Phone: 0684116 30000, E-mail: benedikt.braun@uks.eu 